\title{
Purification of urine samples to improve detection limit of anabolic agents
}

\author{
Madhusudhana I. Reddy, A. Beotra*, S. Jain, T. Kaur, Ranjit Lal
}

Dope Control Centre, Sports Authority of India, J. N. Stadium,

New Delhi - 110 003, India

Received: 31.3 .2006

Revised: 8.8 .2006

Accepted: 30.8 .2006

Correspondence to:

A. Beotra

E-mail: drabeotra@rediffmail.com

\section{Introduction}

The International Olympic Committee (IOC) and World AntiDoping Agency (WADA) have banned the use of anabolic androgenic steroids (AAS) in sports in 1976 and 2002, respectively. To impose the ban, urine samples of sport persons are tested for anabolic steroids and their metabolites by Gas Chromatography-Mass Spectrometer (GC-MS) and highresolution mass spectrometer (HRMS). ${ }^{[1]}$ The samples are extracted for unconjugated and conjugated steroids with varying chemical properties. After extraction, the steroids are derivatized to yield trimethyl silyl derivatives for detection by GC/MS and HRMS. Use of HRMS for AAS has improved the detection limit of few steroids viz nandrolone, stanozolol, epimetendiol and clenbuterol. Approximately 50 AAS fall in the WADA banned list. ${ }^{21}$ The detection limit for all anabolic steroids is $10 \mathrm{ng} / \mathrm{mL}$ except clenbuterol, nandrolone, stanozolol, methyl testosterone, and epimetendiol that are to be detected at $2 \mathrm{ng} / \mathrm{mL}$ in urine samples. These four drugs are to be detected in lower concentration compared to rest of anabolic steroids (detection limit is $10 \mathrm{ng} / \mathrm{mL}$ ); hence, sample purification is required to facilitate detection at $2 \mathrm{ng} /$ $\mathrm{mL}$. Sample preparation also needs improvement to improve the detection limit of these steroids apart from improved instrumentation. Improvement of sample preparation may be achieved by the use of various solid phase extraction procedures, ${ }^{[3-5]}$ HPLC clean up ${ }^{[6,7]}$ or Immunoaffinity Chromatography (IAC) gels..$^{[8-11]}$ The objective of present study was to investigate the recovery percentage of clenbuterol, nandrolone, stanozolol, and epimetendiol by two simple solid phase extraction procedures, using XAD2 and SPE columns.

\section{Materials and Methods}

Reference standards and chemicals

The reference standards of clostebol and clenbuterol were 
purchased from Sigma-Aldrich (St Louis, MO, USA) and of nandrolone, stanozolol, epimetendiol from National Analytical Research Laboratory (National Measurement Institute, Sydney, Australia). The derivatizing reagent N-methyl-NTrimethysilyltrifluoroacetamide (MSTFA), iodo-TMS and Dithioerythritol were purchased from Sigma-Aldrich (St Louis, MO, USA). The hydrolyzing enzyme $\beta$-glucuronidase, $E$. coli is purchased from Roche, Germany. All other reagents and chemicals such as methanol, diethyl ether, and anhydrous sodium sulphate were of analytical grade or HPLC grade.

Two types of solid phase extraction columns were used. The Amberlite XAD2 was purchased from Sigma-Aldrich (St Louis, MO, USA) and C-18 Samprep; $100 \mathrm{mg} / 3 \mathrm{~mL}$ from Rankem, India was purchased.

\section{Extraction procedure}

The samples were processed by XAD2 extraction ${ }^{[12]}$ and SPE column.

XAD2 extraction: About $2 \mathrm{~mL}$ of centrifuged urine was passed into pre-prepared XAD2 column and $50 \mathrm{~mL}$ of clostebol (conc. $2.5 \mathrm{ng} / \mathrm{mL}$ ) was added as the internal standard. The column was eluted with $2.5 \mathrm{~mL}$ of methanol and the eluent dried under nitrogen evaporator at $60^{\circ} \mathrm{C}$. To this was added $1 \mathrm{~mL}$ of $0.2 \mathrm{M}$-phosphate buffer $\mathrm{pH}-7.0$ and $50 \mu \mathrm{L}$ of $\beta$-glucuronidase $(E$. coli) and the mixture was incubated at $60^{\circ} \mathrm{C}$ for 60 minutes. The hydrolysate was alkalinized by adding $250 \mu \mathrm{L}$ of $7 \%$ potassium carbonate solution to adjust the $\mathrm{pH}$ of the mixture between 9 and 10 . About $5 \mathrm{~mL}$ of distilled diethyl ether was added and mixed by moderate horizontal mixing in the shaker for 10 minutes. The ether layer was transferred to a labeled, glass test tube and the ether evaporated at $60^{\circ} \mathrm{C}$ under the nitrogen evaporator. After evaporation of diethyl ether the tube was placed for 10-15 minutes in a dessicator containing $\mathrm{P}_{2} \mathrm{O}_{5}$, to remove traces of moisture if any.

SPE extraction: SPE columns were conditioned with $2 \mathrm{~mL}$ of methanol and equal amount of distilled water. The procedure followed was similar to that of XAD2 extraction.

\section{Derivatization procedure}

The dried residue was dissolved in $50 \mu \mathrm{L}$ of MSTFA/iodoTMS/dithioerythritol (1000/2/2:v/v/w) mixture. The mixture was incubated at $60^{\circ} \mathrm{C}$ for $15 \mathrm{~min}$ and then transferred into $200 \mu \mathrm{L}$ conical glass vials. Nearly $2 \mathrm{~mL}$ was injected into HRMS for analysis.

\section{Instrumentation and conditions}

HRMS was used for evaluation of concentration of the samples. The parameters of gas chromatograph [Table 1] and Mass Spectrometer [Table 2] are mentioned.

\section{Results}

\section{Limit of detection (LOD)}

Limit of detection was defined as the lowest level at which a compound could be identified in urine samples, with diagnostic ions present with a signal to noise $(\mathrm{S} / \mathrm{N})$ ratio greater than 3. A single diagnostic ion 405.2640, 546.3493, 335.0690, and 448.3193 was used to determine the LOD of nandrolone, stanozolol, clenbuterol, and epimetendiol in urine sample, respectively, by HRMS. The

\section{Table 1}

\begin{tabular}{ll} 
Instrumental parameters of gas chromatograph \\
\hline Instrument & Agilent $6890 \mathrm{GC}, 7679$ automatic liq- \\
& uid sampler \\
& Automatic split, split ratio $11: 1$ \\
Injection mode & $2 \mu \mathrm{L}$ \\
Injection volume & $290^{\circ} \mathrm{C}$ \\
Injector port temperature & $120 \mathrm{kpa}$ helium at $180^{\circ} \mathrm{C}$ (constant \\
Carrier flow & pressure) \\
& $180^{\circ} \mathrm{C}$ for $1 \mathrm{~min}, 229^{\circ} \mathrm{C}$ at $3^{\circ} \mathrm{C} / \mathrm{min}, 300^{\circ} \mathrm{C}$ \\
Oven program & at $40^{\circ} \mathrm{C} / \mathrm{min}$, final hold for $3 \mathrm{~min}$ \\
& Ultra 1 , fused silica, $0.2 \mathrm{~mm} \mathrm{I.D.} \times 17 \mathrm{~m}$ \\
Column & length column, film thickness: $0.11 \mu \mathrm{m}$
\end{tabular}

\section{Table 2}

\begin{tabular}{ll} 
Instrumental parameters of high resolution mass \\
spectrometer \\
\hline Instrument & JEOL JMS-700 M Satation \\
Tune tune & Auto \\
Tune peak width & $0.5 \mathrm{amu}$ \\
Acquisition mode & Selective ion monitoring \\
lon current & $300 \mu \mathrm{A}$ \\
lonizing energy & $70 \mathrm{eV}$ \\
Resolution & 10000 \\
Workstation & Unix workstation \\
\hline
\end{tabular}

\section{Table 3}

Mean recovery of Nandrolone in spiked urine samples with XAD2 and SPE columns

\begin{tabular}{lccc}
\hline \multirow{2}{*}{$\begin{array}{l}\text { Spiked } \\
\text { concentration } \\
(\boldsymbol{n g} / \mathbf{m L})^{*}\end{array}$} & \multicolumn{2}{c}{$\begin{array}{c}\text { Concentration recovered } \\
\text { Mean } \pm \text { SE }(\mathbf{n g} / \mathbf{m L})\end{array}$} & \multirow{P}{*}{ value } \\
\cline { 2 - 3 } & XAD2 & SPE & \\
\hline 1 & $0.3087 \pm 0.4039$ & $0.6708 \pm 0.1627$ & 0.075 \\
2 & $1.0882 \pm 0.1275$ & $1.3326 \pm 0.1289$ & 0.026 \\
5 & $3.0686 \pm 0.3650$ & $2.8080 \pm 0.3322$ & 0.615 \\
10 & $6.3979 \pm 0.5388$ & $7.2279 \pm 0.6567$ & 0.070 \\
\hline
\end{tabular}

${ }^{*} n=6$ samples for each concentration

\section{Table 4}

Mean recovery of stanozolol in spiked urine samples with XAD2 and SPE columns

\begin{tabular}{lccc}
\hline \multirow{2}{*}{$\begin{array}{l}\text { Spiked } \\
\text { concentration } \\
(\mathbf{n g} / \mathbf{m l})^{*} \mathbf{n = 6}\end{array}$} & \multicolumn{2}{c}{$\begin{array}{c}\text { Concentration recovered } \\
\text { Mean } \pm \text { SE }(\mathbf{n g} / \mathbf{m L})\end{array}$} & \multirow{2}{*}{$\boldsymbol{P}$-value } \\
\cline { 2 - 3 } & $\boldsymbol{X A D 2}$ & $\boldsymbol{S P E}$ & \\
\hline 5 & $4.2462 \pm 0.4382$ & $3.6081 \pm 0.3135$ & 0.345 \\
10 & $5.3439 \pm 0.4636$ & $6.5573 \pm 0.4967$ & 0.226 \\
20 & $11.9424 \pm 0.6465$ & $4.1893 \pm 0.3705$ & 0.000 \\
40 & $23.6920 \pm 1.8582$ & $13.0167 \pm 1.2055$ & 0.000 \\
\hline
\end{tabular}

${ }^{*} n$ is the number of samples for each concentration 
LODs of clenbuterol and epimetendiol as required by WADA is $2 \mathrm{ng} / \mathrm{mL} \cdot{ }^{21}$

Recovery, accuracy, and precision

The preliminary work was done with six spiked urine samples of each of clenbuterol, nandrolone, and epimetendiol at $1,2,5$, and $10 \mathrm{ng} / \mathrm{mL}$ and stanozolol at 5, 10, 20, and $40 \mathrm{ng} / \mathrm{mL}$ and were analyzed with HRMS. The results showed that for nandrolone and stanozolol the drug recovery at various concentrations (upto $10 \mathrm{ng} / \mathrm{mL}$ ) was not different between two columns [Tables 3 and 4]. At 20 and $40 \mathrm{ng} / \mathrm{mL}$,

Figure 1: Total ion chromatogram of clenbuterol and epimetendiol of SPE columns

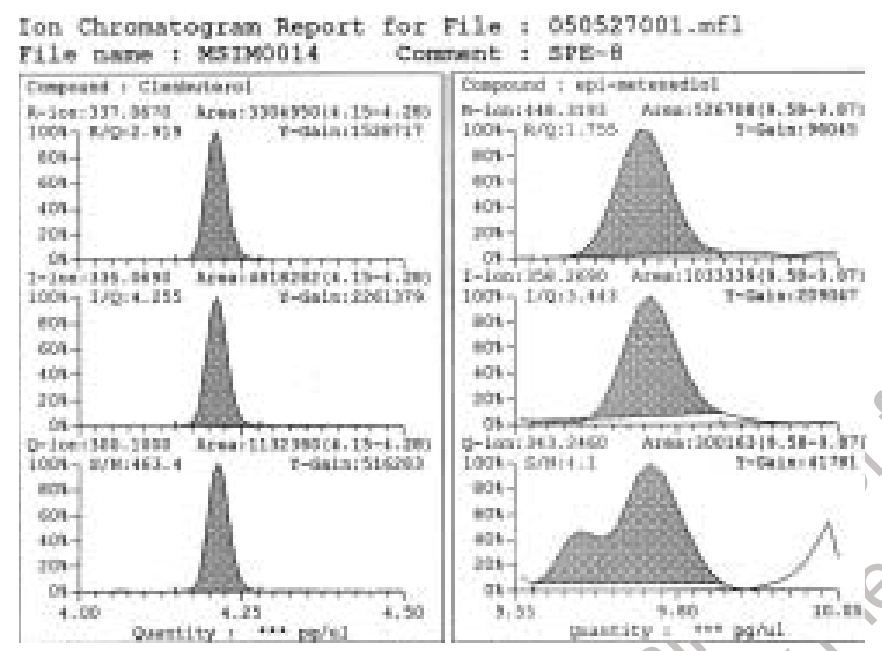

recovery of stanozolol was significantly more $(P<0.00)$ with XAD2 columns.

In a later study the extraction accuracy of the sample preparation procedure with three concentrations of clenbuterol and epimetendiol was undertaken $(n=10)$ and processed with XAD2 and SPE columns.

Clenbuterol. The percentage recovery was $30.45,46.63$, and $41.60 \%$ with XAD2 and $72.09,72.16$, and $89.24 \%$ with SPE columns [Table 5]. The recovery percentage was significantly higher with SPE column extraction. The significance levels were

Figure 2: Total ion chromatogram of clenbuterol and epimetendiol of XAD2 columns

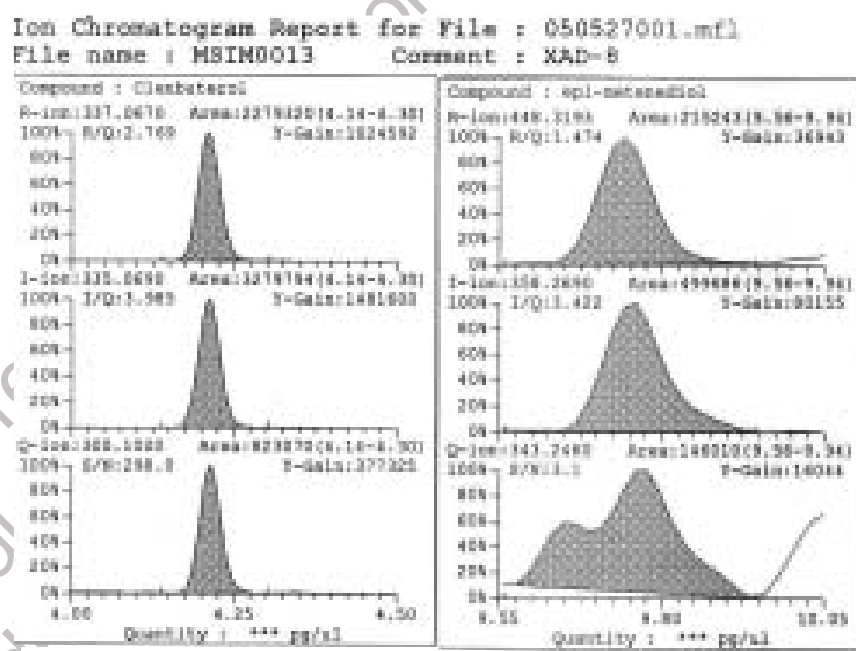

\section{Table 5}

Recovery \% of clenbuterol and epimetendiol in spiked urine samples with XAD2 and SPE columns

\begin{tabular}{|c|c|c|c|c|}
\hline Spiked concentration & \multicolumn{3}{|c|}{ Recovery percentage (Mean \pm SE) } & \\
\hline \multirow[t]{2}{*}{$(n g / m L)^{*} n=10$} & \multicolumn{2}{|c|}{ Clenbuterol } & \multicolumn{2}{|c|}{ Epimetendiol } \\
\hline & XAD2 & $S P E$ & XAD2 & SPE \\
\hline 2 & $30.455 \pm 0.097$ & $72.095 \pm 0.180$ & $105.00 \pm 0.294$ & $136.87 \pm 0.351$ \\
\hline 5 & $46.934 \pm 0.325$ & $72.164 \pm 0.222$ & $69.69 \pm 0.585$ & $104.69 \pm 0.468$ \\
\hline 10 & $41.606 \pm 0.732$ & $89.245 \pm 0.661$ & $66.63 \pm 1.082$ & $99.65 \pm 1.228$ \\
\hline
\end{tabular}

${ }^{*} n$ is the number of samples for each concentration

\section{Table 6}

Mean recovery of clenbuterol and epimetendiol in spiked urine samples with XAD2 and SPE columns

Spiked concentration

$(n g / m L)^{*} n=10$

$(n g / m L)^{*} \mathrm{n}=10$

2

5

10

Within-day spiked mean $\pm S E(n g / m L)$ of recovered drug

\begin{tabular}{cccc}
\hline \multicolumn{2}{c}{ Clenbuterol } & & \multicolumn{2}{c}{ Epimetendiol } \\
XAD2 & SPE & XAD2 & SPE \\
$0.6091 \pm 0.09$ & $1.4419 \pm 0.18$ & $2.13 \pm 0.29$ & $3.41 \pm 0.35$ \\
$2.3467 \pm 0.32$ & $3.6082 \pm 0.22$ & $3.48 \pm 0.58$ & $5.23 \pm 0.46$ \\
$4.1606 \pm 0.73$ & $8.9245 \pm 0.66$ & $6.66 \pm 1.08$ & $9.96 \pm 1.22$ \\
\hline
\end{tabular}

${ }^{*} n$ is the number of samples for each concentration 
$P<0.002(2 \mathrm{ng} / \mathrm{mL}), P<0.001$ (5 and $10 \mathrm{ng} / \mathrm{mL}$ ).

Epimetendiol. The recovery percentage for 2, 5, and $10 \mathrm{ng} / \mathrm{mL}$ with XAD2 were 105, 69.69, 66.63, and 136.87, 104.69 , and $99.65 \%$ with SPE [Table 5]. The recovery percentage was significantly higher with SPE column extraction. The significance level were, $P<0.015(2 \mathrm{ng} / \mathrm{mL})$, $P<0.010(5 \mathrm{ng} / \mathrm{mL})$ and $P<0.014(10 \mathrm{ng} / \mathrm{mL})$.

The recovery of clenbuterol and epimetendiol at 2, 5, and $10 \mathrm{ng} / \mathrm{mL}$ were calculated individually for XAD2 and SPE columns [Table 6]. The total ion chromatogram of clenbuterol and epimetendiol with both XAD2 and SPE columns is shown in Figures 1 and 2.

\section{Discussion}

The results of the present study reveal that the extraction procedure for nandrolone involving XAD2 column, is good and there is no additional advantage using SPE column. With both types of columns nandrolone recovery was comparable. However, there is no available literature on comparison of these two types of columns for nandrolone recovery, though both types of columns have been studied separately. ${ }^{[4,5]}$

The recovery of stanozolol at 5 and $10 \mathrm{ng} / \mathrm{mL}$ was comparable in both types of columns, whereas recovery was significantly more $(P<0.000)$ at 20 and $40 \mathrm{ng} / \mathrm{mL}$ with XAD2 extraction. However, improvement in recovery of Stanozolol at higher concentration (20 and $40 \mathrm{ng} / \mathrm{mL}$ ) is not of much value because it is required to improve detection at lower concentration (2 and $5 \mathrm{ng} / \mathrm{mL}$ ). The purification techniques for Stanozolol reported are Immunoaffinity chromatography (IAC) ${ }^{[9]}$ and use of Oasis cartridges.

There was a significant increase in the recovery of clenbuterol and epimetendiol at different concentrations, which necessitates the need to do confirmation testing with C 18 SPE columns. Though use of C-18 Sep-pak columns for extraction of clenbuterol has been reported. ${ }^{[13]}$ There is no stady comparing recovery percentage of two types of extraction, Further use of SPE columns for epimetendiol extraction has not been reported in literature so far. The purification techniques used for epimetendiol are based on HPLC clean up ${ }^{[6]}$ and IAC gels. ${ }^{\left[{ }^{[6]}\right.}$

\section{Conclusion}

Based on the present work it is concluded that recovery of Clenbuterol and Epimetendiol has improved with SPE columns compared to existing XAD2 columns at various concentrations. Hence, it can be used for confirmation of samples found positive for clenbuterol and epimetendiol.

\section{References}

1. Schanzer W, Opfermann G, Donike M. Metabolism of stanozolol: Identification and synthesis of urinary metabolites. J Steroid Biochem 1990;36:153-74.

2. World Antidoping Agency. The World Anti-Doping Code-The 2006 Prohibited list. $1^{\text {st }}$ January-2006.

3. Tseng YL, Kuo F, Sun KH. Quantification and profiling of 19-Norandrosterone and 19-Noretiocholonalone in human urine after consumption of a nutritional supplement and norsteroids. J Anal Toxicol 2005;29:124-34.

4. Kress A, Mareck-Engelke U, Geyer H, Schanzer W. Alternative bulk materials to XAD2 (Serdolit AD-II), editors. Recent advances in doping analysis Primary (10). Sport und Buch Straub, Koln: 2002. p. 205-9.

5. Uralets VP, Gillette PA, Latven RK. Occurrence of 19-norandrosterone/ Etiocholonalone in Nandrolone positive specimens. Recent advances in doping analysis Primary (4). Sport und Buch Straub, Koln: 1996. p. 35-41.

6. Schanzer W, Delahaut P, Geyer H, Machnik M, Horning S. Long-term detection and identification of metandienone and Stanozolol abuse in athletes by gas chromatography-high-resolution mass spectrometry. J Chromatography 1996;687:93-108.

7. Schanzer W, Opfermann G, Donike M. 17-Epimerization of 17a-methyl anabolic steroids in humans: Metabolism and synthesis of 17a-hydroxy-17b-methyl steroids. Steroids 1992;57:537-50.

8. Machnik M, Delahaunt P, Horning S, Schanzer W. Purification and concentration of anabolic steroids by Immunoaffinity chromatography (IAC). Recent advances in doping analysis Primary (4). Sport und Buch Straub, Koln: 1996. p. 223-37.

9. Schanzer W, Delahaunt P, Volker E, Donike M. Immunoaffinity chromatography in Isolation of Anabolic steroids. Recent advances in doping analysis Primary (2). Sport und Buch Straub, Koln: 1993. p. 307-19.

10. Robinson N, Cardis A, Dienes C, Schanzer M, Saugy, Rivier L. Immunoaffinity chromatography combined with the ion trap technique in order to detect traces of 19-norandrosterone. Recent advances in doping analysis Primary (6). Sport und Buch Straub, Koln: 1998. p. 131-43.

11. Weller MG. Immunochromatographic techniques-a critical review. Fresenius J Anal Chem 2000;366:635-45.

12. Jain S, Ueki M, Ikekita A, Beotra A, Okano M, Sato M, et al. Dope testing during the $1^{\text {st }}$ Afro-Asian Games in India. Indian J Traumatol 2004;5:78-89.

13. Ayottee C. Clenbuterol: Screening and Confirmation. Recent advances in doping analysis Primary (2). Sport und Buch Straub, Koln: 1993. p. 185-96.

\section{Author Help: Reference checking facility}

The manuscript system (www.journalonweb.com) allows the authors to check and verify the accuracy and style of references. The tool checks the references with PubMed as per a predefined style. Authors are encouraged to use this facility before submitting articles to the journal.

- The style as well as bibliographic elements should be $100 \%$ accurate to get the references verified from the system. A single spelling error or addition of issue number / month of publication will lead to error to verifying the reference.

- Example of a correct style

Sheahan P, O'leary G, Lee G, Fitzgibbon J. Cystic cervical metastases: Incidence and diagnosis using fine needle aspiration biopsy. Otolaryngol Head Neck Surg 2002;127:294-8.

- $\quad$ Only the references from journals indexed in PubMed would be checked.

- $\quad$ Enter each reference in new line, without a serial number.

- $\quad$ Add up to a maximum 15 reference at time.

- If the reference is correct for its bibliographic elements and punctuations, it will be shown as CORRECT and a link to the correct article in PubMed will be given.

- If any of the bibliographic elements are missing, incorrect or extra (such as issue number), it will be shown as INCORRECT and link to possible articles in PubMed will be given. 